\title{
Capturing the aftermarket in engineering organizations: opportunities and challenges
}

\author{
Stewart Johnstone, Andrew Dainty and Adrian Wilkinson
}

\begin{abstract}
The provision of additional services to accompany the sale of products is increasingly central to the business strategies of companies in manufacturing and engineering, often referred to as aftermarket services (AMS). The purpose of this paper is to explore the experience of expanding AMS in the context of a leading organization in the engineering sector. The paper explores the meaning of - and rationale for - AMS provision and the manifestations of aftermarket service offerings. AMS enthusiasts envisage an array of benefits including: higher margins, better exploitation of an installed asset base and smoother revenue streams. However, the paper reveals that whilst organizations may find lifecycle AMS attractive, the transition to becoming an integrated provider of product and AMS is likely to be more complex than much of the extant literature suggests.
\end{abstract}

Index Terms - aftermarket services, integration solutions, solutions, service

\section{INTRODUCTION AND BACKGROUND}

$\mathrm{T}$ HE growth of services is one of the major trends of recent years and is reflected in the changing structures of contemporary economies in Europe, Asia and the USA where services now account for the majority of employment, as well as the bulk of national output. Nevertheless, the term 'service' is applied to a heterogeneous range of activities. One definition offered by Kotler [2003, 625] is "any activity or benefit that one party can offer to another which is essentially intangible, and does not result in the ownership of anything". Indeed intangibility is often identified as one of the key characteristics of a service. Other prototypical characteristics include that services are often perishable, difficult to standardise, and do not have a separate point of production/consumption [Lovelock and Gummesson, 2004]. Of course service activities and service jobs are not exclusive to traditional service industries such as hospitality or finance;

Stewart Johnstone, Department of Civil and Building Engineering, Loughborough University, LE11 3TU, UK. (Email: s.johnstone@,lboro.ac.uk. ( Corresponding Author) Tel: +44(0) 1509228799 Fax: +44 (0) 1509223981 Andrew Dainty, Department of Civil and Building Engineering, Loughborough University,

Adrian Wilkinson, Department of Employment Relations, Griffith Business School, Griffith University, Nathan, QLD 4111, Australia indeed there is rarely such a thing as a 'pure good' or 'pure service'. The notion of a 'service mix' suggests that offerings can more usefully be thought of as a continuum ranging from 'tangible dominant' at one end, through to 'intangible dominant' at the other [Kotler, 2003; Cohen et.al, 2006].

In recent years there has been a proliferation of research into traditional 'product-dominant' organizations which aim to increase the value of their offerings by either augmenting their product offering with services or by integrating products and services into a single joined up system. Various terms have been used to describe a general trend away from a 'pure product' orientation towards expanding aftermarket services (AMS) through life. These include 'servicisation' [Quinn et.al, 1990], 'servitization' [Vandermerwe and Rada, 1988; Van Looy et.al, 1998], 'going downstream' [Wise and Baumgartner, 1999], 'winning in the aftermarket' [Cohen et.al, 2006] 'integrated solutions' [Davies et.al, 2006, 2007] 'product-service systems' [Baines et.al, 2007)] and 'new manufacturing' [Marceau et.al 2002]. However, at the core of most of these phrases is a concern with the provision of additional services which are complementary to a tangible product in order to increase the value for customers. This is founded upon the belief that the boundaries between 'product' and 'service' have become increasingly blurred [Lester, 1998; Marceau et.al, 2002; Lovelock, 2007]. In particular, there is the suggestion that product manufacturers should be attempting to integrate services into their core product offerings to remain competitive [Bowen et.al, 1991; Gadiesh and Gilbert, 1998; Quinn et.al, 1990, Wise and Baumgartner, 1999]. As Cohen et.al comment, "This is the golden age of services, and to survive and prosper, we're told every company must transform itself into a services business" [Cohen et.al, 2006].

Opportunities for enhanced service offerings can, in part, be viewed as a response to the trend of large private sector organizations and governments towards outsourcing many operational and systems integration activities [Davies et.al, 2006; Lojo, 1997]. It may also be viewed as a pragmatic response to the saturation and commoditisation of core product markets, increased price pressure, decreasing product margins and global competition [Gebauer et.al, 2005; Sawhney, 2004]. Benefits for the provider are said to include services often being more profitable than physical products, a source of differentiation in a competitive marketplace, as well 
as leading to additional demand for products [Anderson et.al, 1997, Heskett et.al, 1997]. Other benefits are said to include lengthening customer relationships, creating growth opportunities in mature markets, balancing the effects of economic cycles, and in providing capabilities in responding to changing client demands [Brax, 2005].

It has been recognised that further research is required to explore the experiences of organizations undertaking the transition from product manufacturer to service provider [Oliva and Kallenberg, 2003], as the current literature offers little insight into how attempts to integrate products and services occur and the challenges organizations encounter [Windahl and Lakemond, 2006]. Accordingly, this paper aims to explore what AMS mean in the context of the engineering sector and to understand the rationale for developing AMS. Moreover, it aims to understand some of the key tensions and challenges to effective AMS provision, by juxtaposing the aspirational intent with the operational complexities that bundling product/AMS offerings presents.

This paper presents findings from an engineering organization which would traditionally be thought of as primarily providing tangible goods. In such organizations, the provision of accompanying services to clients has often been thought of as a low value, low status activity. Though services of some description have almost always been offered, they have normally been considered to be peripheral, and concerned only with routine and reactive maintenance to support the product. Service arrangements have often been given away 'free' in order to clinch a potentially lucrative product order. However, many 'product' organizations are increasingly engaging in 'through-life service' in addition to their traditional product offering. Thus, the traditional view of service as a 'bolt-on' is changing, as traditional 'product' organizations revise their business models in an attempt to transform their service operations from a 'necessary evil' cost centre, into strategically important, lucrative profit centres [Lele, 1997].

\section{METHOD}

Given the research aim to understand more about how and why AMS strategies play out in different contexts, as well as the need to understand the meanings actors associate with the notion, a case study approach was deemed most appropriate (Yin 2003). More specifically, a degree of 'purposive sampling' was employed (Patton 1990), with the organization demonstrating important characteristics (ostensibly involved in and committed to expanding AMS, large, multi-site, international, engineering). This paper draws upon 20 interviews with a range of senior managers and operational personnel conducted in the organization between April 2006 and April 2007. Interviews were semi-structured and typically between 45 and 90 minutes in duration. All date were transcribed verbatim and analysed under thematic headings. The interview data was also supplemented with internal company documentation which explained the strategies and structures devised for delivering AMS.

\section{DEVELOPING AFTERMARKET SERVICES AT ENGCO}

EngCo is a leading power and automation technology company organised around divisions focused on products and systems. They have clients across a diverse range of industries including Oil and Gas, Food and Beverage, Pulp and Paper, as well as in the Utility sector. Their espoused vision is to be a global leader in power and automation technologies enabling utility and industry customers to improve their performance while lowering their environmental impact. Strategically, the organization is argued to be 'moving along the value chain' from its position as an international electrical engineering company in the 1980 s, to a global engineering and technology company in the 2000s. During the 1990 s, growth, diversification and acquisitions were said to be the mantra, but following an extremely turbulent period in the early 2000 s, the strategy has been refined as the business focuses upon its core power and automation strengths and offerings. This was viewed an acknowledgement of the popular adage "size is vanity, profit is sanity".

Over time, the global organization has become increasingly interested in providing 'cradle to cradle' asset management over extended product lifecycles, as opposed to the more traditional product sale with a package of routine maintenance offerings. This is thought to be a particularly successful and well established business model in other industries and parts of the world. In fact, it was suggested that through-life service has a long history in the copper and mining industries of the Americas, and the pulp and paper industries of the Nordic countries. In the UK electrical engineering context, opportunities have been identified in industries including chemicals, food processing, electronics and automotive. The rationale for developing service operations include cycles in product demand, customer demand for support to large and ageing installed base, ongoing product commoditisation in some areas, potentially higher margins with smoother sustainable revenue streams. Service revenues were viewed as a more reliable income stream in contrast to the peaks and troughs of demand for product. Retaining the customer through the life of the product and offering a migration path through to new technology was also identified as an opportunity. Service was said to help the 'marketing loop' whereby established relationships and proved product performance support the opportunity to introduce new products to the customer in the future. This also supported 'knowledge retention' within the business due to more stable staffing levels. Reflecting the heterogeneity of clients, industries and technological environments in which EngCo operate, the service portfolio is extremely diverse ranging from supplying spare parts through to full maintenance outsourcing.

At EngCo, the development of AMS varied by division. For example, the Automation business had developed a portfolio of different service offerings to meet the needs of the different industry sectors they serve. These ranged from routine 
maintenance contracts in some parts of the instrumentation business, through to maintenance of high voltage equipment of electricity substations in the Utilities market. The service package delivered depends on the 'value in use'. Where the consequences of failure can be very high, for example on an oil rig, these sectors demand premium service. Where the consequences of system failure are moderately high such as factory production line or airport conveyor belts, these require mid-range responsiveness. In parts of the lower complexity commodity business, the products can to some extent be serviced by local providers which means that service attracts lower rates. The most sophisticated model of 'AMS', however, is Complete Service Provision Contracts. Complete Service Provision is a 'risk-reward' maintenance programme aimed at capturing the market of manufacturing organizations which have attempted to streamline their businesses in recent years, often by 'outsourcing' their internal workforce. Effectively, a partnership is entered into between EngCo and the client organization involving the sharing of risk, jointly agreed objectives, and shared rewards where efficiency improvements/process improvements are made. Under this arrangement, EngCo take over responsibility for the engineering, planning, execution, and management of an entire plant's maintenance activity. Importantly, this offering was conceived as a "cradle-to-cradle" solution, where the long-term relationship and understanding of the customer's business which evolved enabled them to also work towards developing the next generation of product and service to support their business. Potential benefits for Complete Service Provision clients are said to include performance/efficiency improvements, reliability, a more strategic/continuous improvement maintenance operation, continuous access to EngCo's knowledge, and the creation of a service mindset and culture. An explicit commitment is normally made to increase Overall Equipment Effectiveness and decrease maintenance costs through a system of bonuses and penalties. To date, the UK the market for Complete Service Provision has been modest, but further opportunities are thought to exist within the Automation business. Challenges include pulling customers through to this new business model, as well as the likelihood of increased competition in this arena as the model gains popularity. They also have to accept the economies of the diverse industries in which they operate. For example, while pulp and paper is experiencing consolidation and intense global competition, the oil and gas sector is extremely buoyant and many North Sea assets are aging and reaching obsolescence.

The Power business is concerned with products and services which predominantly support the products and systems in the Utilities market including transformers, switchgear, \& circuit breakers. Services include diagnostics, migration and upgrades, retrofit, refurbishment, training, spares and maintenance and field services offered through a network of field service technicians. Benefits for the clients are said to include trouble free operation, maximum asset availability, improved performance, and reduced costs in terms of operation, maintenance and capital. Within this sector the market dynamics have encouraged a slightly different strategy, focusing upon preventative and corrective maintenance, rather than on the more comprehensive 'Complete Service Provision' model encountered within the automation business. While a complete maintenance outsourcing model may be developing in the automation sectors, the model is less advanced in the Utility sector, where asset intensive clients tend to retain a stronger commitment to keeping engineering maintenance teams in-house.

\section{DISCUSSION}

The study has explored how AMS is understood and enacted in a leading organization in the engineering sector. The organization espoused an AMS vision, in terms of the desire to move away from a traditional reactive product-focused business model towards one of long-term customer orientation. However, despite the frequent use of terms such as 'through-life service', 'product-service' and 'integrated solution' there are no agreed definitions as to what each specifically means, and usage varied within and between division. Though EngCo have always provided some form of service, there are several important differences in terms of the new timescales [through-life as opposed to ad hoc], strategic importance [central rather than peripheral] and potential value [high value rather than low value]. Rhetorically at least, there is the connotation of a more intimate long-term relationship between the organization and its clients [Galbraith, 2002, Oliva and Kallenberg, 2003] an element of risk sharing, and the expectation that AMS can be mutually beneficial. The rationale resonates with the reasons presented in the existing literature where traditional OEM firms now endeavour to provide through-life service support in order to create new business, protect intellectual property, provide a form of differentiation, and increase value for the customer [Mathieu, 2001; Oliva and Kallenberg, 2003; Ward and Graves, 2007].

Interestingly, AMS had been enacted in a piecemeal and ad hoc ways in the two divisions. EngCo espoused a number of divisional AMS strategies supported by a general group infrastructure. Tensions lay in determining where the locus of control of the divisions and the group support services resided. It was unclear as to who had responsibility for ensuring that the AMS offers were maintained through robust and aligned systems and procedures. The company also appeared to be encountering a challenge in that different parts of the business moving at different speeds with regards AMS provision. This had led to parallel business strategies being enacted in the Power and Automation divisions, each of which demanded a different set of strategies in relation to other aspects of the business.

The case organization also appeared to be facing various challenges in delivering AMS included ambiguity around the service strategy, embedding a service culture, and fragmentation. Clearly within diversified businesses there was a lack of a clear corporate service strategy, reflecting the different histories, trajectories and technologies of the different divisions. In addition, developing services was only 
one of a multitude of different business strategies being implemented simultaneously. A common theme was the need to transform the culture of the organization in a context of strongly embedded product-centric, engineering-biased OEM 'engineering culture' which it was believed often resides within large heterogeneous and decentralised organizations [Bowen et.al, 1988; Gebauer et.al, 2005]. This was reinforced by managerial systems in terms of incentives and metrics which appeared to perpetuate a product-orientation. Under the old service model, service was sometimes viewed as an ad hoc, low risk 'cash cow' for the organization and often existed as a department bolted-on to the organization as a whole [Lele, 1997]. In a sense, product organizations actually benefited when their product failed and a lucrative repair opportunity arose [Gebauer and Fleisch, 2007]. The new business model requires a longer-term view of the business in product organizations with embedded output-driven cultures focused upon sales targets, order books and quarterly results. This is likely to be essential if the organization is to become closer to the customer in order to gain an insight into the world in which they operate, shifting away from a service supporting the product, towards a service supporting the client [Mathieu, 2001]. A focus on 'culture change' alone is not enough; rather there is a need for a more fundamental review of management practices [Oliva and Kallenberg, 2003], and the extent to which they support or hinder business strategy. Given the lack of alignment of management structures and business strategies it is unsurprising that there is a lack of employee buy-in at the grassroots. The fragmented nature of the organizations was a recurring challenge. The old 'product' business model was characterised by dividing the business into specialist component parts. However, AMS provision requires that product, sales and service organizations are now forced to work together but little mutual empathy traditionally exists. A clear challenge is a lack of co-operation and co-ordination within divisionalised, highly fragmented organizational structures [Miller et.al, 2002; Windahl and Lakemond, 2007]. The case study highlights what can occur when different parts of the organization are not integrated.

Overall the study has highlighted the complexity of developing AMS propositions, and in turn questions the inevitable oversimplifications made in the literature regarding successful recipes or blueprints for the successful delivery of AMS strategies. It is argued that there is an urgent need for a more sophisticated and nuanced understanding of complex sector specific strategies for AMS. As the case study demonstrates there are important differences within the organizations in terms of technologies, products, client demands and economic cycles. It is therefore difficult to see how a particular instrumental solution can be successfully transferred from one part of an organization to another.

\section{CONCLUSION}

This study has highlighted significant limitations of the existing literature and in particular the lack of sensitivity to the different contexts, meanings and manifestations of AMS strategies which exist. As the introductory section made clear, AMS is a broad term applied loosely to a variety of different organizational/management strategies and offerings. As such there is a need for a greater awareness of the different manifestations of AMS. A related question concerns the extent to which espoused organizational AMS offerings are really 'new'. In some cases, it may be used as a new fashionable label for what the organization has always done. In others, it may describe an aspiration but not necessarily where the organization is, or where it is going. There is also the possibility that organizations may have captured some of new aspects of AMS but that the business model has not yet changed.

The literature appears to oversimplify the complex, emergent realities of AMS is delivered as a result of the normative nature of current AMS prescriptions. The formula for success appears deceptively simple, with a general consensus emerging around, for example, the 'need to restructure', 'develop capabilities', and facilitate 'cultural change'. Our study reveals that the reality of AMS delivery is quite different, and that the process is not as linear as the current literature implies [see for example Oliva and Kallenberg [2003]; Van Looy et.al 1998]. The literature implies a neat change process comprising unfreezing, changing, and refreezing [Lewin, 1951]. The case study in this research suggest that this view attempts to solidify a complex and dynamic process occurring in an environment characterised by perpetual transition, rather than 'quasi-stationary equilibrium' [Weisbord, 1988, 94]. The organizations were all highly fragmented, decentralised pluralist coalitions, in stark contrast to the unitarist assumptions underpinning much of the 'best practice' literature. In addition, there was little evidence of a single paradigm; but rather multiple business strategies were evident. Coalescing different business streams around a single offering is bound to lead to tensions. There is a need for a more sophisticated understanding of the emergent realities and manifestations of AMS. This may reflect the methodological limitations of the literature. Gebauer et.al [2006], for example, base their 'success factors for high service revenues', upon one day site visits to five organizations which they had identified as 'successful' in service revenue terms. Respondents were asked to hypothesise as to the potential success factors during the growth of service revenues. Inevitably, this can only provide a crude snapshot into such a complex phenomenon.

The lack of a critical debate around the issues discussed in this paper needs to be addressed. Many studies take for granted that a transition to AMS is happening and that it should be happening. Often the significant risks involved are overlooked. The problematic realities of concurrently enacting different strategies for AMS integration across different business streams appear disconnected from the nostrums and overly simplistic models which pervade the current solutions discourse. As a result the research, like the consultancy literature, is overwhelmingly normative focusing on establishing 'roadmaps' to the much-vaunted high service revenues. Yet the recommendations tend to be vague and 
rhetorical, offering little real guidance. They also overlook the variety of paths to AMS which this study has demonstrated. It is worth remembering that the number of manufacturing organizations achieving a high share of total revenues through services remains very low [Gebauer and Fleisch, 2007]. Undoubtedly engineering organizations may be finding potential service revenues alluring, but any roadmap to success in the aftermarket remains elusive.

\section{ACKNOWLEDGMENT}

The contributions of our project team and our industrial collaborators are gratefully acknowledged. The project is funded by the Engineering and Physical Sciences Research Council [EPSRC] and the Economic and Social Research Council [ESRC] under Grant Numbers EP/C534220/1 and RES-331-27-0006.

\section{REFERENCES}

[1] Anderson, E. Fornell, C. and Rust, R. [1997] Customer satisfaction, productivity and profitability: differences between goods and services, Marketing Science, 16(2) pp129-45.

[2] Baines, T. Lightfoot, H. Evans, S. Neely, A. Greenough, R. Peppard, J. Roy, R. Shehab, E. Braganza, A. Tiwari, A. Alcock, J. Angus, J. Basti, M. Cousens, A. Irving, P. Johnson, M. Kingston, J. Lockett, H. Martinez, V. Michele, P. Tranfield, D. Walton, J. and Wilson, H. (2007) State of the art in product-service systems, Journal of Engineering Manufacture Part B, pp1543-1551.

[3] Bowen, D. Siehl, C. and Schneider, B. [1989] A framework for analysing customer service orientations in manufacturing, Academy of Management Review, 14, p.75.

[4] Brax, S. [2005] 'A manufacturer becoming service provider-challenges and a paradox', Managing Service Quality, 15 [2], 142-155.

[5] Cohen, M. Argrawal, N and Arawal, V [2006] Winning in the aftermarket, Harvard Business Review, May, 129-138.

[6] Davies, A. Brady T. and Hobday, M. (2006) Charting a path towards integrated solutions, MIT Sloan Management Review, Spring 38-4.

[7] Gadiesh, O. and Gilbert, J [1998] "Profit pools: a fresh look at strategy", Harvard Business Review, 76(3), 139-47.

[8] Galbraith, J. [2002] Organizing to deliver solutions, Organizational Dynamics, 31(2), pp.194-207.

[9] Gebauer, H., Beckenbauer, B. and Fleisch, E. [2004], "How to innovate customer support services in manufacturing firms?", in Edvardsson, B., Gustafsson, A., Brown, S.B. and Jonhston, R. [Eds], Service Excellence in Management: Interdisciplinary Contributions, Proceedings of the QUIS 9 Conference, Karlstad, June 15-18, pp. 397-406.

[10] Gebauer, J. Fleisch, E. and Freidli, T. [2005] Overcoming the service paradox in manufacturing companies, European Management Journal, 23(1) pp.14-26.

[11] Heskett, J. Sasser, W. and Schlesinger, L. [1997] The Service Profit Chain, Free Press, New York.

[12] Kotler, P [2003] Marketing management, Pearson Education, New York.

[13] Lele, M. [1997] After-sales service: necessary evil or strategic opportunity? Managing Service Quality, 7[3], pp.141-145.

[14] Lester, R [1998] The productive edge - How US industries are pointing the way to a new era of economic growth, New York: Norton.

[15] Lewin, K. [1951] Field Theory in Social Science, Harper and Row, New York.

[16] Lojo, M. [1997] Contracting for high technology industrial services, Sloan School of Management.
[17] Lovelock, C. and Gummesson, E. (2004) Whither services marketing: in search of a new paradigm and fresh perspectives, Journal of Service Research, 7(1), pp.20-41

[18] Lovelock, C. [2007] The non-ownership society: when goods become services, $21^{\text {st }}$ Service Workshop, University of Westminster, London.

[19] Marceau, J. Cook, N. Dalton, B. and Wixted, B. [2002] Selling solutions: emerging patterns of product-service linkage in the Australian economy, Australian Expert Group in Industry Studies [AEGIS], University of Western Sydney.

[20] Mathieu, V. [2001] Product services: from a service supporting the product to a service supporting the client, Journal of Business and Industrial Marketing, 16[1] pp. 39-58.

[21] Oliva, R. and Kallenberg, R. [2003] Managing the transition from products to services, International Journal of Service Industry Management, 14[2], pp.160-172.

[22] Patton, M. Q. (1990). Qualitative evaluation and research methods (2nd ed.). Newbury Park, CA: Sage Publications.

[23] Quinn, J. B., Doorley, T. L. and Paquette, P. C. [1990] 'Beyond products: services-based strategy', Harvard Business Review, 68 [2], 5860, 64-6, 68 .

[24] Sawhney, M. [2004] Creating growth with services, Sloan Management Review, Winter, pp.34-43.

[25] Vandermerwe, S. and Rada, J. 1988 Servitization of business: adding value by adding service, European Management Journal

[26] Van Looy, B Gemmel, P, Desmet, S, van Deerdonck, R, Seernels, S 1988 Dealing with productivity and service quality indicators in a service environment: some field experiences, International Journal of Service Industry Management, 9[4].

[27] Ward, Y. Graves, A. [2007] Through life management: the provision of total customer solutions in the aerospace industry, International Journal of Services Technology Management, 8(6), pp. 455-477.

[28] Windahl, C. and Lakemond, M. [2006] Developing integrated solutions: the importance of relationships within the network, Industrial Marketing Management, 35(7), pp. 806-818/

[29] Wisbord, M.R. [1988] Productive workplaces: organising and managing for dignity, meaning and community, Jossey Bass, San Francisco.

[30] Wise, R. and Baumgartner, P. [1999] 'Go Downstream: The New Profit Imperative in Manufacturing '", Harvard Business Review, Sept/Oct, 133-141.

[31] Yin, R. (2003) Case study research, Sage: London. 